\title{
Tat-NOL3 protects against hippocampal neuronal cell death induced by oxidative stress through the regulation of apoptotic pathways
}

\author{
EUN JEONG SOHN ${ }^{1 *}$, MIN JEA SHIN ${ }^{1 *}$, WON SIK EUM ${ }^{1 *}$, DAE WON KIM ${ }^{2 *}$, JI IN YONG ${ }^{1}$, EUN JI RYU ${ }^{1}$, \\ JUNG HWAN PARK ${ }^{1}$, SU BIN CHO ${ }^{1}$, HYUN JU CHA ${ }^{1}$, SANG JIN KIM ${ }^{1}$, HYEON JI YEO ${ }^{1}$, EUN JI YEO ${ }^{1}$, \\ YEON JOO CHOI ${ }^{1}$, SEUNG KWON IM ${ }^{1}$, HAE YOUNG KWEON ${ }^{3}$, DUK-SOO KIM ${ }^{4}$, YEON HEE YU ${ }^{4}$, \\ ${\text { SUNG-WOO } \mathrm{CHO}^{5}, \text { MEEYOUNG PARK }^{1} \text {, JINSEU PARK }}^{1}$, YONG-JUN CHO ${ }^{6}$ and SOO YOUNG CHOI $^{1}$ \\ ${ }^{1}$ Department of Biomedical Science and Research Institute of Bioscience and Biotechnology, Hallym University, \\ Chuncheon, Gangwon-do 24252; ${ }^{2}$ Department of Biochemistry and Molecular Biology, Research Institute \\ of Oral Sciences, College of Dentistry, Gangneung-Wonju National University, Gangneung, Gangwon-do 25457; \\ ${ }^{3}$ Department of Agricultural Biology, National Academy of Agricultural Sciences, RDA, Wanju-gun, Jeollabuk-do 55365; \\ ${ }^{4}$ Department of Anatomy, College of Medicine, Soonchunhyang University, Cheonan-si, Chungnam 31538; \\ ${ }^{5}$ Department of Biochemistry and Molecular Biology, University of Ulsan College of Medicine, Seoul 05505; \\ ${ }^{6}$ Department of Neurosurgery, College of Medicine, Hallym University, Chuncheon, Gangwon-do 24253, Republic of Korea
}

Received July 8, 2015; Accepted April 28, 2016

DOI: $10.3892 / \mathrm{ijmm} .2016 .2596$

\begin{abstract}
Oxidative stress-induced apoptosis is associated with neuronal cell death and ischemia. The NOL3 [nucleolar protein 3 (apoptosis repressor with CARD domain)] protein protects against oxidative stress-induced cell death. However, the protective mechanism responsible for this effect as well as the effects of NOL3 against oxidative stress in ischemia remain unclear. Thus, we examined the protective effects of NOL3 protein on hydrogen peroxide $\left(\mathrm{H}_{2} \mathrm{O}_{2}\right)$-induced oxidative stress and the mechanism responsible for these effects in hippocampal neuronal HT22 cells and in an animal model of forebrain ischemia using Tat-fused NOL3 protein (Tat-NOL3). Purified Tat-NOL3 protein transduced into the $\mathrm{H}_{2} \mathrm{O}_{2}$-exposed HT22 cells and inhibited the production of reactive oxygen species (ROS), DNA fragmentation and reduced mitochondrial membrane potential $\left(\Delta_{\Psi \mathrm{m}}\right)$. In addition, Tat-NOL3 prevented neuronal cell death through the regulation of apoptotic signaling
\end{abstract}

Correspondence to: Dr Soo Young Choi, Department of Biomedical Science and Research Institute of Bioscience and Biotechnology, Hallym University, 1 Hallymdaehak-gil, Chuncheon, Gangwon-do 24252, Republic of Korea

E-mail: sychoi@hallym.ac.kr

Dr Yong-Jun Cho, Department of Neurosurgery, College of Medicine, Hallym University, Chuncheon, Gangwon-do 24252, Republic of Korea E-mail: nssur771@hallym.or.kr

*Contributed equally

Key words: apoptosis, ischemic damage, cell viability, oxidative stress, Tat-fused NOL3 protein, protein therapy pathways including Bax, Bcl-2, caspase-2, -3 and -8, PARP and p53. In addition, Tat-NOL3 protein transduced into the animal brains and significantly protected against neuronal cell death in the CA1 region of the hippocampus by regulating the activation of microglia and astrocytes. Taken together, these findings demonstrate that Tat-NOL3 protein protects against oxidative stress-induced neuronal cell death by regulating oxidative stress and by acting as an anti-apoptotic protein. Thus, we suggest that Tat-NOL3 represents a potential therapeutic agent for protection against ischemic brain injury.

\section{Introduction}

Ischemia-reperfusion injury increases oxidative stress and inflammation as well as provoking oxidative damage to the hippocampal CA1 region of the brain (1). Oxidative stress leads to mitochondrial dysfunction, calcium accumulation, and the increased production of reactive oxygen species (ROS) resulting in post-ischemic reperfusion neuronal death $(2,3)$. The pathophysiology of ischemia-reperfusion injury includes the excessive production of ROS that contributes to tissue damage, both directly through lipid peroxidation, protein oxidation, and DNA damage as well as indirectly through the activation of apoptotic pathways $(4,5)$.

Oxidative stress is known to induce apoptosis, which has been implicated in various types of cell death including ischemic damage to the heart and brain $(6,7)$. Apoptosis may be initiated through the two major pathways of apoptosis, the extrinsic and the intrinsic pathways (8). The intrinsic apoptotic pathway is initiated by stress signals that lead to the translocation of Bax to mitochondria (9), the release of cytochrome $c$ (10) and the associated activation of caspase-3 (11). The extrinsic apoptotic pathway activates death receptors, resulting in death-inducing 
signaling complex (DISC) formation that leads to the activation of caspase- 8 , followed by the activation of caspase-3 (11). p53 is a transcription factor that has been found to induce growth arrest through the transactivation of $\mathrm{p} 21^{\mathrm{cip} 1 / \mathrm{waf} 1}$ and also, to initiate apoptosis in response to DNA damage (12). Caspase-2 is known to mediate intrinsic apoptotic pathway signaling and may be activated by oxidative stress $(7,13)$.

The NOL3 [nucleolar protein 3 (apoptosis repressor with CARD domain)] protein is highly expressed in the heart, skeletal muscle and the brain, and plays a role in the inhibition of physiological apoptotic pathways (7). NOL3 protein contains two functional domains: the CARD and the proline/glutamic acid $(\mathrm{P} / \mathrm{E})$ domains. The CARD domain is similar to the pyrin domain, a small helical death domain that is involved in protein-protein interactions. The CARD domain of the NOL3 protein is capable of downregulating the activity of caspase-2 and -8 by CARD-CARD interactions $(14,15)$.

Protein transduction domains (PTDs) including Tat peptide deliver proteins into cells and tissues by crossing membranes or the blood brain barrier (BBB). Many studies, including those conducted by our group have demonstrated that the Tat fusion proteins efficiently transduce into cells/tissues where they protect against various types of oxidative stress-induced cell death including neuronal cell death (16-25).

Under conditions of oxidative stress, the regulation of ROS, caspases and pro-apoptotic proteins may be crucial therapies for ischemic brain injury. To address this hypothesis, we have demonstrated the protective effect of cell permeable Tat-fused NOL3 protein (Tat-NOL3) on oxidative stress-induced hippocampal HT22 neuronal death and ischemic brain injury.

\section{Materials and methods}

Cell lines and reagents. The mouse hippocampal neuronal cell line, HT22 (from ATCC, Manassas, VA, USA), was cultured in Dulbecco's modifed Eagle's medium (DMEM) (Lonza/ BioWhittaker, Walkersville, MD, USA) containing $10 \%$ fetal bovine serum (FBS) and antibiotics $(100 \mu \mathrm{g} / \mathrm{ml}$ streptomycin, $100 \mathrm{U} / \mathrm{ml}$ penicillin and $100 \mu \mathrm{g} / \mathrm{ml}$ gentamicin sulfate) and cultured in an incubation chamber $\left(37^{\circ} \mathrm{C}, 95 \%\right.$ air and $\left.5 \% \mathrm{CO}_{2}\right)$.

FBS and the antibiotics were purchased from Gibco-BRL (Grand Island, NY, USA). We purchased a $\mathrm{Ni}^{2+}$-nitrilotriacetic acid Sepharose superflow column from Qiagen, Inc. (Valencia, CA, USA) and Tat peptide from Peptron, Inc (Daejeon, Korea). The primary, secondary, and $\beta$-actin antibodies were obtained from Cell Signaling Technology, Inc. (Beverly, MA, USA) and Santa Cruz Biotechnology, Inc. (Santa Cruz, CA, USA). All other chemicals and reagents were of the highest quality grade available.

Animals. Mongolian gerbils (Meriones unguiculatus; body weight, 65-75 g, 6 months of age) were obtained from the Experimental Animal Center at Hallym University (Chuncheon, Korea). The animals were housed at a constant temperature $\left(23^{\circ} \mathrm{C}\right)$ and relative humidity $(60 \%)$ under a fixed 12-h light:12-h dark cycle with unlimited access to food and water. All experimental procedures involving the animals and their care conformed to the Guide for the Care and Use of Laboratory Animals of the National Veterinary Research and Quarantine Service of Korea, and were approved by the Hallym
Medical Center Institutional Animal Care and Use Committee (Chuncheon, Korea).

Expression and purification of Tat-NOL3 protein. The construction of the Tat expression vector was performed as described in our previous study (26). Human NOL3 cDNA was obtained through PCR amplification with the following specific primers: sense primer, 5'-CTCGAGGGCAACGCGCAG-3'; and antisense primer, 5'-GGATCCTCAGGAATCTTCGGA CTC-3'. The PCR product was subcloned in the Tat expression vector with an N-terminal 6His-tag. To obtain the control NOL3 (con-NOL3) plasmid, Tat leader cDNA was deleted from the Tat-NOL3 plasmid. The recombinant Tat-NOL3 plasmid was transformed into Escherichia coli BL21(DE3; Novagen, Madison, WI, USA) cells and then incubated with $0.1 \mathrm{mM}$ isopropyl $\beta$-D-thiogalactoside (IPTG; Duchefa Biochemie, Haarlem, The Netherlands) at $20^{\circ} \mathrm{C}$ for $20 \mathrm{~h}$. The cell homogenates were purified by chromatography using an $\mathrm{Ni}^{2+}$-nitrilotriacetic acid Sepharose affinity column and a PD-10 column (Amersham, Braunschweig, Germany). Quantification of the purified protein was measured by performing a Bradford assay (Bio-Rad Laboratories, Hercules, CA, USA) using bovine serum albumin (BSA) as the standard (27).

Transduction of Tat-NOL3 protein. To analyze the transduction of Tat-NOL3 protein into cells, the HT22 cells were exposed to various concentrations of purified Tat-NOL3 protein $(1-14 \mu \mathrm{M}$, for $1 \mathrm{~h}$ ) or for various time periods $(10-60 \mathrm{~min}$, at $14 \mu \mathrm{M})$. The measurement of the quantity of transduced Tat-NOL3 protein was performed by western blot analysis $(28,29)$. We performed $15 \%$ sodium dodecyl sulfate-polyacrylamide gel electrophoresis (SDS-PAGE) to analyze the protein. After the proteins were transferred from the gel to a nitrocellulose membrane, the membrane was blocked with phosphate buffered saline (PBS) with Tween 20 (PBS-T) containing 5\% non-fat dry milk or BSA. The membrane was probed with a rabbit anti-histidine polyclonal antibody (1:5,000; sc-804, Santa Cruz Biotechnology, Inc.). In addition, to detect apoptosis related-signals in the whole cell lysates, the membrane was immunoblotted using specific antibodies to p21 (2947), p-p53 (9284), p53 (9282), PARP (9532), cleaved PARP (9544), Bax (2772), Bcl-2 (2876), caspase-3 (9662), cleaved caspase-3 (9661), caspase-2 (2224) and caspase-8 (4927) (1:1,000; Cell Signaling Technology, Inc.). In all cases, a horseradish peroxidase-conjugated secondary antibody was used (1:10,000; Cell Signaling Technology, Inc.). The proteins were detected with enhanced chemiluminescence reagents (Amersham, Franklin Lakes, NJ, USA).

To determine the intracellular stability of Tat-NOL3 protein, the cells were treated with Tat-NOL3 for $1 \mathrm{~h}$ and were then incubated further for 1-72 h. Subsequently, the cells were harvested and transduced Tat-NOL 3 protein was detected using a rabbit anti-histidine polyclonal antibody.

Immunostaining analysis. The cells were cultured on coverslips placed in wells of a tissue culture plate and treated with Tat-NOL3 protein $(14 \mu \mathrm{M})$. The samples were incubated at $37^{\circ} \mathrm{C}$ for $1 \mathrm{~h}$ and washed with PBS twice after which they were then fixed with $4 \%$ paraformaldehyde for $5 \mathrm{~min}$ at room temperature. Subsequently, the cells were incubated with $3 \%$ BSA, $0.1 \%$ Triton X-100 and PBS (PBS-BT) for $30 \mathrm{~min}$ 
at room temperature, and washed twice with PBS-BT. The primary antibody (His-probe; Santa Cruz Biotechnology, Inc.) was diluted 1:2,000 and the cells were exposed for $2 \mathrm{~h}$ at room temperature. The cells were incubated in the dark for $1 \mathrm{~h}$ with Alexa Fluor 488-conjugated secondary antibody (Invitrogen, Carlsbad, CA, USA) diluted 1:15,000. To stain the nuclei, $1 \mu \mathrm{g} /$ ml DAPI (Roche Applied Science, Basel, Switzerland) was added for $2 \mathrm{~min}$. Analysis was performed under a confocal fluorescence microscope (FA-300; Olympus, Tokyo, Japan) $(23,30)$.

Cell viability assay. Cell viability was evaluated as described previously $(31,32)$. Briefly, the HT22 cells were exposed to $1 \mu \mathrm{M}$ hydrogen peroxide $\left(\mathrm{H}_{2} \mathrm{O}_{2}\right)$ for $16 \mathrm{~h}$ following treatment with Tat-NOL3 or con-NOL3 protein. Cell viability was determined using a WST-1 assay kit according to the manufacturer's instructions (Daeil Lab Service Co., Seoul, Korea). Absorbance was measured at $450 \mathrm{~nm}$ with an enzyme-linked immunosorbent assay (ELISA) microplate reader (Multiskan MCC/340; Thermo Labsystems Oy., Helsinki, Finland). Cell viability is presented as a percentage of the control.

Measurement of ROS levels. The ROS level was evaluated as previously described (29). Briefly, the HT22 cells were treated with $0.5 \mathrm{mM} \mathrm{H}_{2} \mathrm{O}_{2}$ for 20 min following treatment with Tat-NOL 3 or con-NOL3 protein. To measure the intracellular ROS levels, the cells were treated with 2'-,7'-dichlorofluorescein diacetate (DCF-DA) which is converted into 2'-,7'-dichlorofluorescein (DCF) by $\mathrm{H}_{2} \mathrm{O}_{2}$. Cell fluorescence image intensity was measured at 485-nm excitation and 538-nm emission using a Fluoroskan ELISA plate reader (Thermo Labsystems Oy.). Control cell images were obtained using differential interference contrast (DIC), which is used in images of cell morphology.

Analysis of DNA fragmentation by terminal deoxynucleotidyl transferase (TdT)-mediated biotinylated dUTP nick-end labeling (TUNEL) assay. Tat-NOL3 protein $(14 \mu \mathrm{M})$ or con-NOL3 protein was transduced into the HT22 cells for $1 \mathrm{~h}$ prior to exposure to $0.5 \mathrm{mM} \mathrm{H}_{2} \mathrm{O}_{2}$ for $16 \mathrm{~h}$. DNA fragmentation was detected by TUNEL staining using a Cell Death Detection kit (Roche Applied Science). Images were captured using a fluorescence microscope (Nikon Eclipse 80i; Nikon, Tokyo, Japan) (23).

5,5',6,6'-tetrachloro-1,1',3,3'-tetraethylbenzimidazoly-carbocyanine iodine (JC-1) mitochondrial membrane potential $\left(\Delta_{\Psi m}\right)$ assay. To examine $\Delta_{\Psi \mathrm{m}}, 14 \mu \mathrm{M}$ Tat-NOL3 protein or $14 \mu \mathrm{M}$ con-NOL3 protein was transduced into the HT22 cells for $1 \mathrm{~h}$ and subsequently, they were exposed to $0.5 \mathrm{mM} \mathrm{H}_{2} \mathrm{O}_{2}$ for $2 \mathrm{~h} . \Delta_{\Psi_{\mathrm{m}}}$ was assessed as described previously $(33,34)$. Briefly, $100 \mu \mathrm{l}$ of JC-1 staining solution per $\mathrm{ml}$ of culture medium was added and the cells were incubated in a $\mathrm{CO}_{2}$ incubator at $37^{\circ} \mathrm{C}$ for $15 \mathrm{~min}$. JC-1 staining was performed according to the manufacturer's instructions using a JC-1 assay kit (Cayman Chemical Company, Inc., Ann Arbor, MI, USA). The cells were then analyzed with a fluorescence microscope using $507 \mathrm{~nm}$ and $530 \mathrm{~nm}$ as excitation and emission wavelengths, respectively. To analyze $\Delta_{\Psi \mathrm{m}}$, the ratio of the reading at $590 \mathrm{~nm}$ to the reading at $530 \mathrm{~nm}$ was considered as the relative $\Delta_{\Psi \mathrm{m}}$ value. Images of each sample were captured using a fluorescence microscope (Nikon Eclipse 80i).
Establishment of an animal model of forebrain ischemia. A model of forebrain ischemia was established as described in previous studies $(35,36)$. Briefly, the animals were anesthetized, common carotid arteries were isolated, freed of nerve fibers, and occluded with non-traumatic aneurysm clips. Complete interruption of blood flow was confirmed by observing the retinal artery using an ophthalmoscope (HEINE K180 ${ }^{\circledR}$, Heine Optotechnik, Herrsching, Germany). After 5 min of occlusion, the aneurysm clips were removed.

To explore the protective effects of Tat-NOL3 protein against ischemic damage, the animals were divided into 5 groups ( $n=10 /$ group); sham-operated group, vehicle (saline)treated group, Tat peptide-treated group, con-NOL3-treated group, and Tat-NOL3-treated group (each $2 \mathrm{mg} / \mathrm{kg}$ ) with ischemic surgery. Tat peptide, con-NOL3 protein, and Tat-NOL3 proteins were administered intraperitoneally $30 \mathrm{~min}$ after ischemia-reperfusion.

Immunohistochemical analysis. To examine the effects of Tat-NOL3 on ischemicdamage, brain tissuesamples wereobtained at 7 days after ischemia-reperfusion. Immunohistochemistry was performed as described previously $(33,35,36)$. The animals were anesthetized with $30 \mathrm{mg} / \mathrm{kg}$ Zoletil 50 (Virbac Laboratories, Carros, France) at 7 days after ischemia-reperfusion and perfused transcardially with $0.1 \mathrm{M}$ PBS ( $\mathrm{pH}$ 7.4) followed by $4 \%$ paraformaldehyde in $0.1 \mathrm{M}$ phosphate buffer ( $\mathrm{pH} 7.4)$. The brains were removed and post-fixed in the same fixative for $6 \mathrm{~h}$. The brain tissue samples were cryoprotected by infiltration with $30 \%$ sucrose overnight. The frozen tissues were then serially sectioned on a cryostat (Leica, Wetzlar, Germany) into $30 \mu \mathrm{m}$ coronal sections to investigate the morphological and neuronal changes in the hippocampus, and subsequently, the sections were collected into 6-well plates containing PBS.

For the histological analysis, the sectioned brains were incubated with mouse anti-neuronal nuclei (NeuN; 1:1,000; Chemicon International, Inc., Temecula, CA, USA), rabbit anti-ionized calcium-binding adapter molecule 1 (Iba-1; 1:500; Wako, Osaka, Japan), and rabbit anti-glial fibrillary acidic protein (GFAP; 1:1,000; Chemicon International, Inc.) for $48 \mathrm{~h}$ at $20^{\circ} \mathrm{C}$. They were then exposed to biotinylated rabbit anti-goat $\operatorname{IgG}(1: 200$; Vector Laboratories, Inc., Burlingame, CA, USA) or goat antimouse IgG and streptavidin-peroxidase complex and visualized with 3,3'-diaminobenzidine (Sigma-Aldrich, St. Louis, MO, USA). Cresyl violet (CV; Junsei Chemical Co. Ltd., Saitama, Japan) and Fluoro-Jade B (FJB; Millipore Co., Temecula, CA, USA) staining were performed as previously described $(23,33)$. Additionally, we performed immunostaining with a rabbit anti-histidine antibody and DAPI to detect the transduction of Tat-NOL3 protein in the brain hippocampus.

Statistical analysis. The data presented represent the means \pm SD from three independent experiments. One way ANOVA and the Student's t-test were used for comparisons between the groups. $\mathrm{P}<0.05$ was considered to indicate a statistically significant difference.

\section{Results}

Purification and transduction of Tat-NOL3 protein into HT22 cells. Transducible Tat-NOL3 proteins were generated by cloning 
A
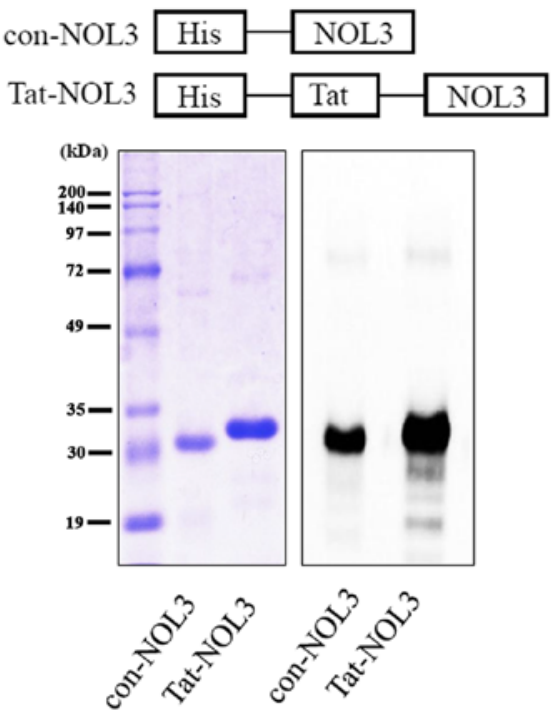

$\mathrm{C}$
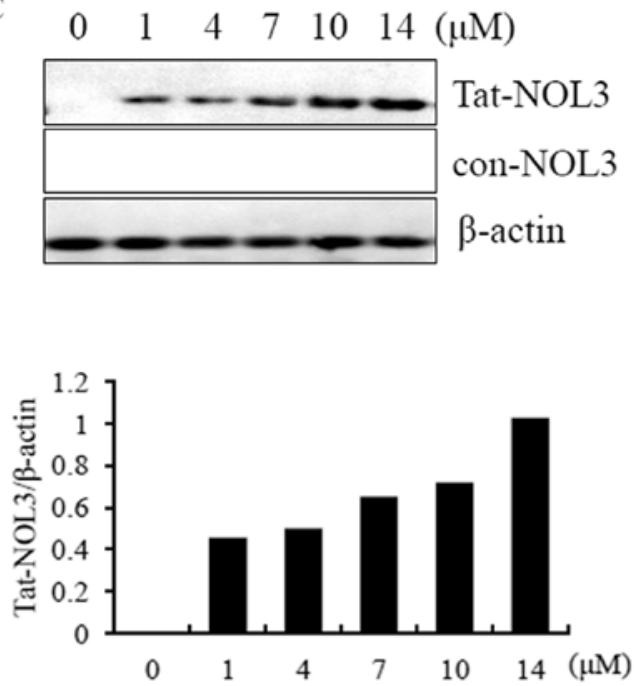

$\mathrm{D}$

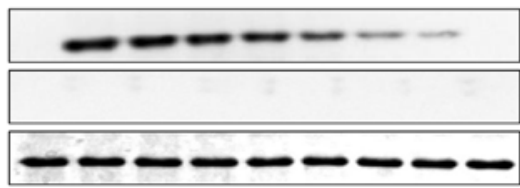

$\begin{array}{llllllllll}0 & 1 & 6 & 12 & 24 & 36 & 48 & 60 & 72 & (\mathrm{~h})\end{array}$
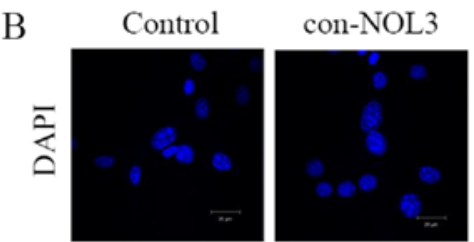

Tat-NOL3
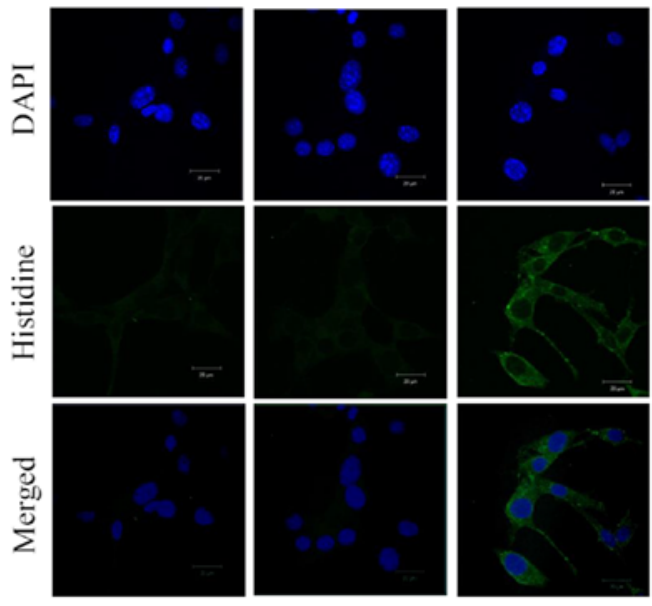

\section{$0 \quad 102030 \quad 4050 \quad 60(\mathrm{~min})$}
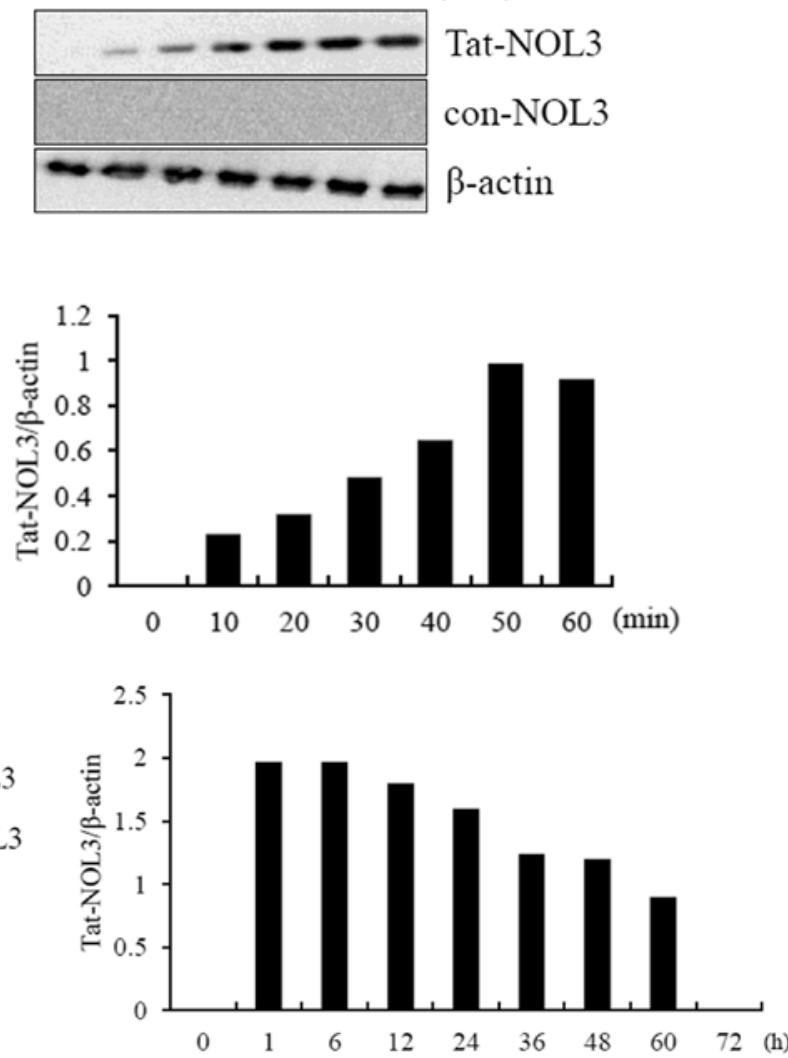

Figure 1. Purification and transduction of Tat-fused (Tat)-NOL3 protein. (A) Schematic diagram of the expressed control (con)-NOL3 and Tat-NOL3 proteins. Each consists of a His tag comprising six histidine residues. Following induction with isopropyl $\beta$-D-thiogalactoside (IPTG), purified con-NOL3 and Tat-NOL3 proteins were analyzed by $15 \%$ SDS-PAGE and western blot analysis with an anti-rabbit polyhistidine antibody. (B) Transduction of Tat-NOL3 protein into HT22 cells. The distribution of the transduced Tat-NOL3 protein was observed by fluorescence microscopy. Scale bar, $50 \mu \mathrm{m}$. (C) The HT22 cells were exposed to various concentrations (1-14 $\mu \mathrm{M}$ for $60 \mathrm{~min}$ ) of Tat-NOL3 or con-NOL3 protein or over various periods of time (0-60 min) and analyzed by western blot analysis. (D) Stability of transduced Tat-NOL3 protein in the HT22 cells was evaluated by western blot analysis and the band intensities were measured by densitometry.

cDNA of NOL3 into the 6 His tags of a Tat-expression vector. To obtain con-NOL3 proteins, the Tat domain was deleted from the Tat-NOL3 construct. Recombinant Tat-NOL3 and con-NOL3 proteins were overexpressed in E. coli BL21(DE3) cells by IPTG induction. The Tat-NOL3 and con-NOL3 proteins were purified using an $\mathrm{Ni}^{2+}$-nitrilotriacetic acid Sepharose affinity column and each Tat-NOL3 and con-NOL3 protein was evaluated by SDS-PAGE and western blot analysis using an anti-rabbit polyhistidine antibody (Fig. 1A). To examine the localization of Tat-NOL3 protein in the cells, transduced Tat-NOL3 proteins were stained with nuclear and cytosolic markers, DAPI and Alexa Fluor 488-conjugated secondary antibody, respectively. As shown in Fig. 1B, con-NOL3 proteins were undetectable in the HT22 cells. Differing from the con-NOL3 proteins, the 


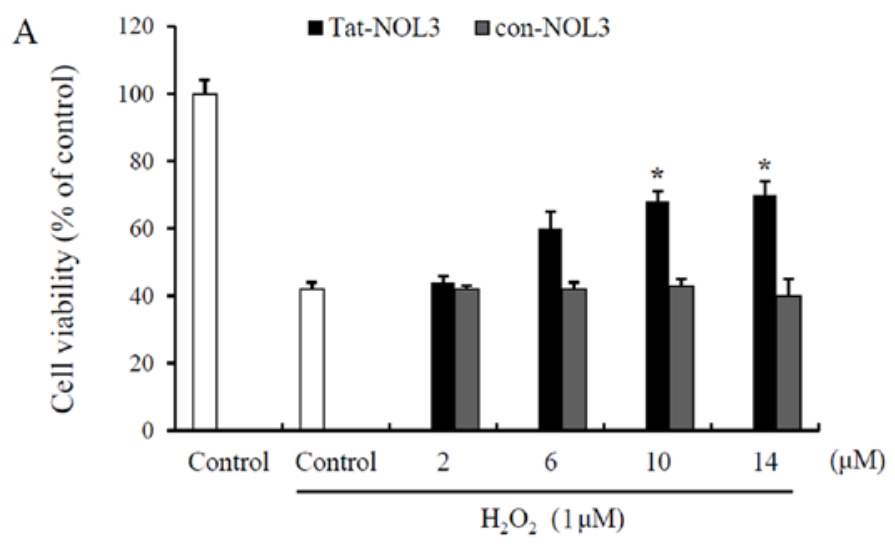

B
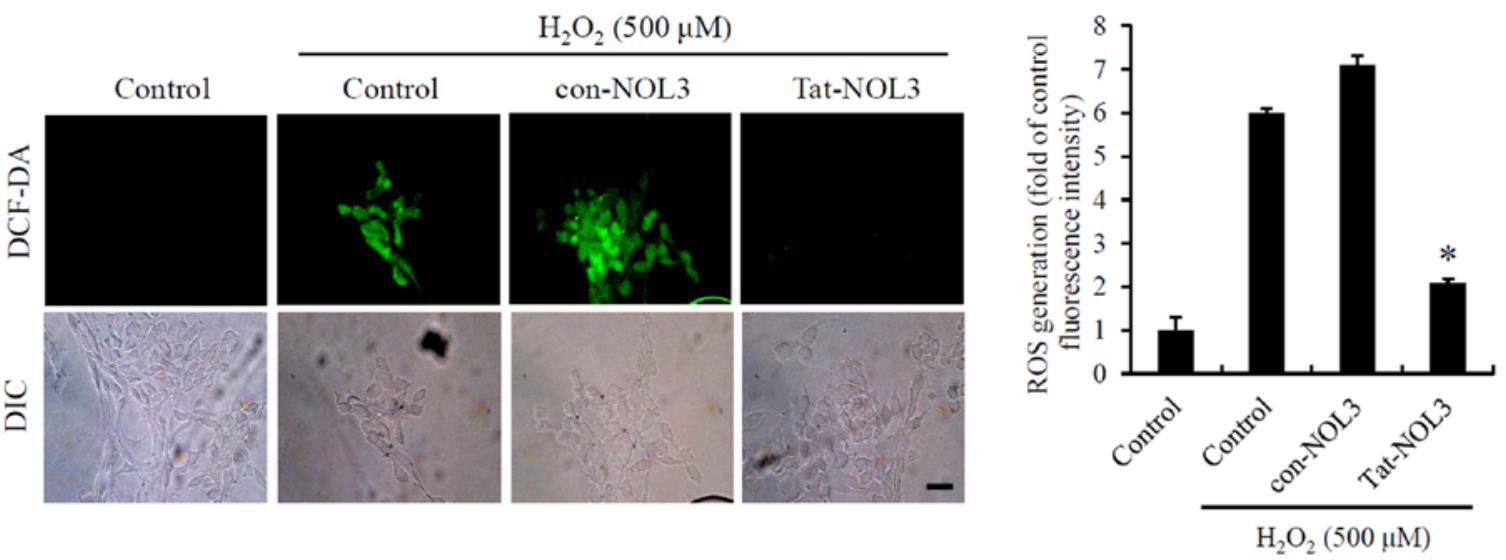

Figure 2. Effect of Tat-fused (Tat)-NOL3 protein on cell viability and levels of intracellular reactive oxygen species (ROS) in $\mathrm{H}_{2} \mathrm{O}_{2}$-exposed $\mathrm{HT} 22$ cells (A) HT22 cells were treated with Tat-NOL3 or control (con)-NOL3 proteins for $1 \mathrm{~h}$ prior to the addition of $1 \mu \mathrm{M} \mathrm{H}_{2} \mathrm{O}_{2}$ to the culture medium for $16 \mathrm{~h}$. Cell viability was measured with a colorimetric assay using WST-1. (B) HT22 cells were treated with Tat-NOL3 or con-NOL3 (14 $\mu \mathrm{M})$ proteins for $1 \mathrm{~h}$ prior to the addition of $500 \mu \mathrm{M} \mathrm{H}_{2} \mathrm{O}_{2}$ to the culture medium for $20 \mathrm{~min}$. Intracellular ROS levels were determined by DCF-DA staining. Images of each sample were captured using a fluorescence microscope and DIC images. " $\mathrm{P}<0.01$, compared with $\mathrm{H}_{2} \mathrm{O}_{2}$-exposed cells. Scale bar, $50 \mu \mathrm{m}$.

transduced Tat-NOL3 proteins were mainly detected in the cytoplasm by fluorescence microscopy. We also evaluated the permeability of Tat-NOL3 proteins and con-NOL3 proteins in the hippocampal neuronal HT22 cells. Tat-NOL3 protein transduction into the HT22 cells gradually increased in a dose(1-14 $\mu \mathrm{M})$ and time-dependent (10-60 min) manner (Fig. 1C). In addition, intracellular stability of transduced Tat-NOL3 protein existed in the cells for a maximum of $60 \mathrm{~h}$ (Fig. 1D).

Tat-NOL3 protein increases cell viability and inhibits ROS-induced DNA fragmentation and mitochondrial dysfunction in HT22 cells. Ischemia-reperfusion is associated with ROS generation in tissues (37). To determine the effects of Tat-NOL 3 protein on $\mathrm{H}_{2} \mathrm{O}_{2}$-exposed HT22 cells, we treated the HT22 cells with Tat-NOL3 or con-NOL3 prior to $\mathrm{H}_{2} \mathrm{O}_{2}$ exposure. We then measured the ability of Tat-NOL3 protein to inhibit $\mathrm{H}_{2} \mathrm{O}_{2}$-induced cell death and ROS generation. The cell viability of the $\mathrm{H}_{2} \mathrm{O}_{2}$-treated cells was $42 \%$. However, cell viability increased in a dose-dependent manner up to $70 \%$ in the cells treated with Tat-NOL3 protein whereas con-NOL3 protein did not exert a protective effect against $\mathrm{H}_{2} \mathrm{O}_{2}$-induced cell death (Fig. 2A). In addition, we measured the degree of ROS generation using fluorescence microscopy. In the $\mathrm{H}_{2} \mathrm{O}_{2}$ and con-NOL 3 protein-treated HT22 cells, fluorescence signals were strongly detected. However, the fluorescence signals were markedly decreased in the Tat-NOL3 protein treated cells (Fig. 2B). These results indicate that transduced Tat-NOL3 prevents cell death caused by $\mathrm{H}_{2} \mathrm{O}_{2}$-induced ROS production.

Mitochondria are a major cellular source of ROS production. Ischemia-reperfusion is known to induce changes in $\Delta_{\Psi \mathrm{m}}$ resulting in mitochondrial dysfunction $(3,9)$. To examine whether Tat-NOL3 protein exerts an effect on $\Delta_{\Psi_{\mathrm{m}}}$, the HT22 cells were exposed to $\mathrm{H}_{2} \mathrm{O}_{2}$. As shown in Fig. $3 \mathrm{~A}, \Delta_{\Psi \mathrm{m}}$ changes in the cells treated with con-NOL3 protein were strongly induced following exposure to $\mathrm{H}_{2} \mathrm{O}_{2}$ whereas transduced Tat-NOL3 protein protected against $\Delta_{\Psi \mathrm{m}}$ changes in the $\mathrm{H}_{2} \mathrm{O}_{2}$-exposed HT22 cells and $\Delta_{\Psi \mathrm{m}}$ changes were similar to those observed in the normal control group. Thus, it seems reasonable to conclude that transduced Tat-NOL3 protein plays a role in protecting cells against mitochondrial dysfunction.

ROS production contributes to apoptotic cell death and DNA fragmentation after ischemia-reperfusion injury $(38,39)$. Tat-NOL3 protein suppressed ROS-induced mitochondrial dysfunction in the HT22 cells. Consistent with this, we determined the effect of Tat-NOL3 protein on $\mathrm{H}_{2} \mathrm{O}_{2}$-induced DNA fragmentation in the HT22 cells by performing a TUNEL assay. TUNEL-positive cells were detected in the $\mathrm{H}_{2} \mathrm{O}_{2}$-treated control group and the con-NOL3 protein-treated group. However, TUNEL-positive cells were only slightly detected in the Tat-NOL3 protein-treated group (Fig. 3B). These results indicate that Tat-NOL3 inhibits ROS-induced DNA fragmentation in HT22 cells. 
A
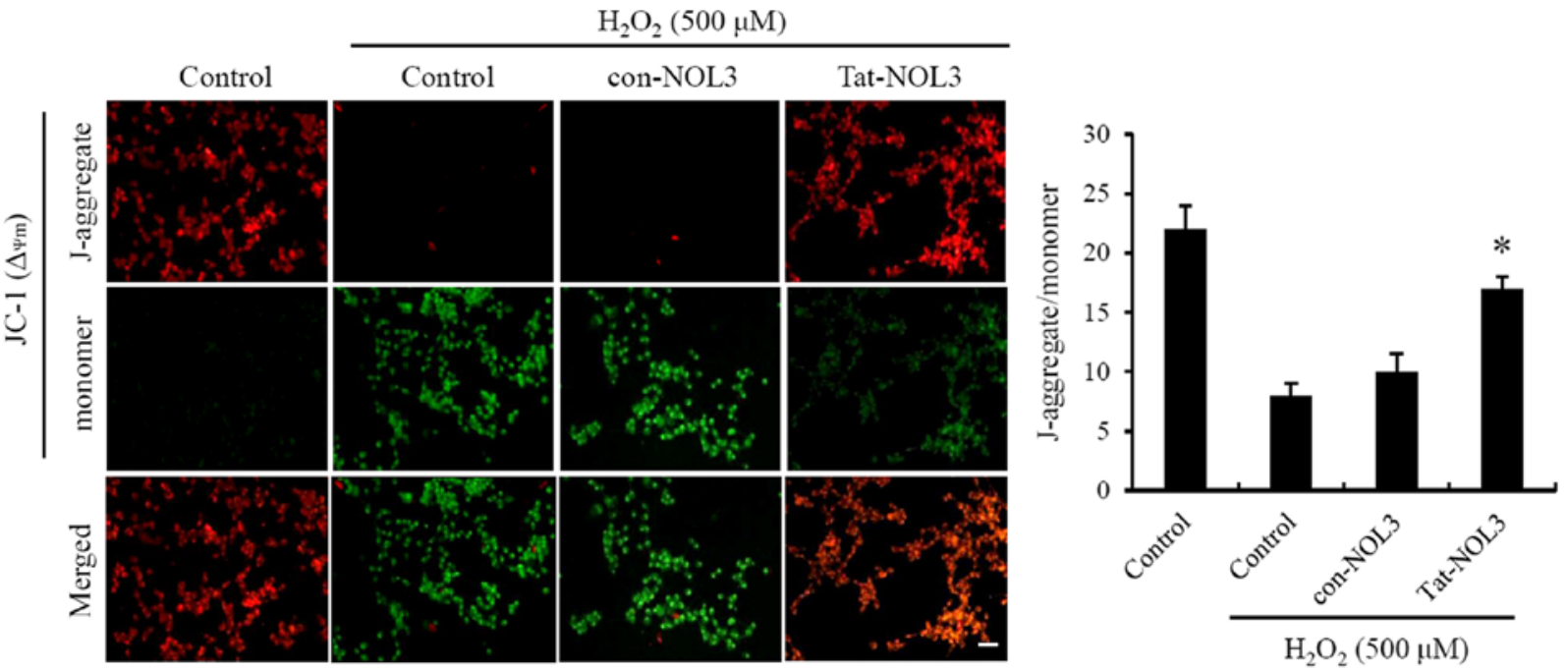

B
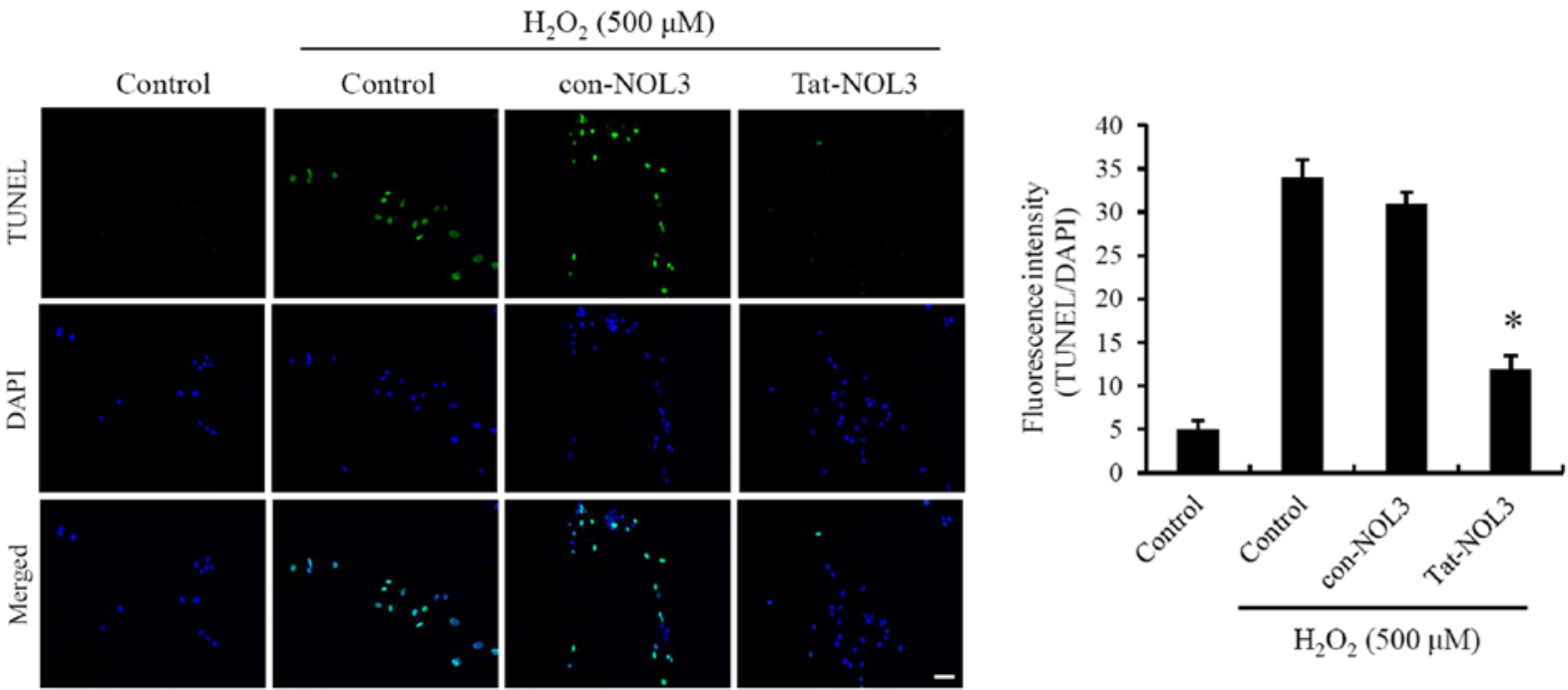

Figure 3. Effects of transduced Tat-fused (Tat)-NOL3 protein on mitochondria membrane potential $\left(\Delta_{\Psi_{\mathrm{m}}}\right)$ and DNA fragmentation in $\mathrm{H}_{2} \mathrm{O}_{2}$-exposed $\mathrm{HT} 22$ cells. (A) Tat-NOL3 protein was transduced for $1 \mathrm{~h}$, and the cells were exposed to $500 \mu \mathrm{M} \mathrm{H}_{2} \mathrm{O}_{2}$ for $2 \mathrm{~h} . \Delta_{\Psi_{\mathrm{m}}}$ was evaluated by JC-1, using a mitochondrial membrane potential assay kit. (B) Tat-NOL3 protein was transduced for $1 \mathrm{~h}$, and the cells were exposed to $500 \mu \mathrm{M} \mathrm{H}_{2} \mathrm{O}_{2}$ for $16 \mathrm{~h}$. DNA fragmentation was detected by TUNEL staining. Images were captured using a fluorescence microscope. " $\mathrm{P}<0.01$, compared with $\mathrm{H}_{2} \mathrm{O}_{2}$-exposed cells. Scale bar, $50 \mu$ m; con-NOL3, control NOL3.

The activation of $\mathrm{p} 53$ by elevated ROS levels elicits cell cycle arrest or apoptosis (40). Oxidative DNA damage, which may result in DNA fragmentation causing cells to undergo cycle arrest followed by apoptotic cell death (38). It has been demonstrated that excessive ROS levels induce increased levels of $\mathrm{p} 21^{\text {cipl/wafl }}$ (p21) and decreased levels of cleaved-PARP in a p53 dose-dependent manner (41). Thus, we examined the effect of Tat-NOL3 protein on p53 function in $\mathrm{H}_{2} \mathrm{O}_{2}$-stimulated HT22 cells. Tat-NOL 3 protein inhibited the phosphorylation of $\mathrm{p} 53$ in the presence of $\mathrm{H}_{2} \mathrm{O}_{2}$, whereas con-NOL3 protein demonstrated no effect on $\mathrm{H}_{2} \mathrm{O}_{2}$-stimulated p53 phosphorylation. However, Tat-NOL3 protein did not change p53 expression levels in the $\mathrm{H}_{2} \mathrm{O}_{2}$-exposed HT22 cells (Fig. 4). In addition, we examined the correlation between Tat-NOL3 protein and oxidative DNA damage in $\mathrm{H}_{2} \mathrm{O}_{2}$-exposed $\mathrm{HT} 22$ cells. With gradually increasing doses of Tat-NOL3 protein, the levels of p21 and cleaved-PARP markedly decreased whereas PARP levels increased. However, con-NOL3 protein did not demonstrate the same effects on $\mathrm{p} 21$ and PARP expression levels (Fig. 4). These findings suggest that Tat-NOL3 inhibited p53-induced oxidative DNA damage through the regulation of p21 and PARP expression levels in the HT22 cells.

Tat-NOL3 protein inhibits ROS-induced apoptosis in HT22 cells. ROS are associated with the caspase-dependent apoptotic pathways and $\mathrm{H}_{2} \mathrm{O}_{2}$ is known to be a potent pro-apoptotic stimulus (42). To examine the effect of Tat-NOL3 protein on ROS-induced apoptosis in HT22 cells, the cells were transiently exposed to $0.5 \mathrm{mM} \mathrm{H}_{2} \mathrm{O}_{2}$ for $20 \mathrm{~min}$ and the expression of Bax, Bcl-2, caspase-2 and -8, cleaved caspase-3, and caspase- 3 were detected using western blot analysis. The expression levels of Bax and cleaved-caspase- 3 were increased whereas the expression levels of Bcl-2, caspase-2 and -3 were decreased by $\mathrm{H}_{2} \mathrm{O}_{2}$. Notably, transduced Tat-NOL3 protein markedly decreased the expression levels of Bax and cleaved caspase-3, whereas it increased the expression levels of Bcl-2, caspase-3 and -8. However, con-NOL3 protein did not affect the expression of apoptosis-related proteins in the $\mathrm{H}_{2} \mathrm{O}_{2}$-exposed HT22 cells (Fig. 5). These results indicate that $\mathrm{H}_{2} \mathrm{O}_{2}$ acts as pro-apoptotic stimulus, whereas transduced Tat-NOL3 

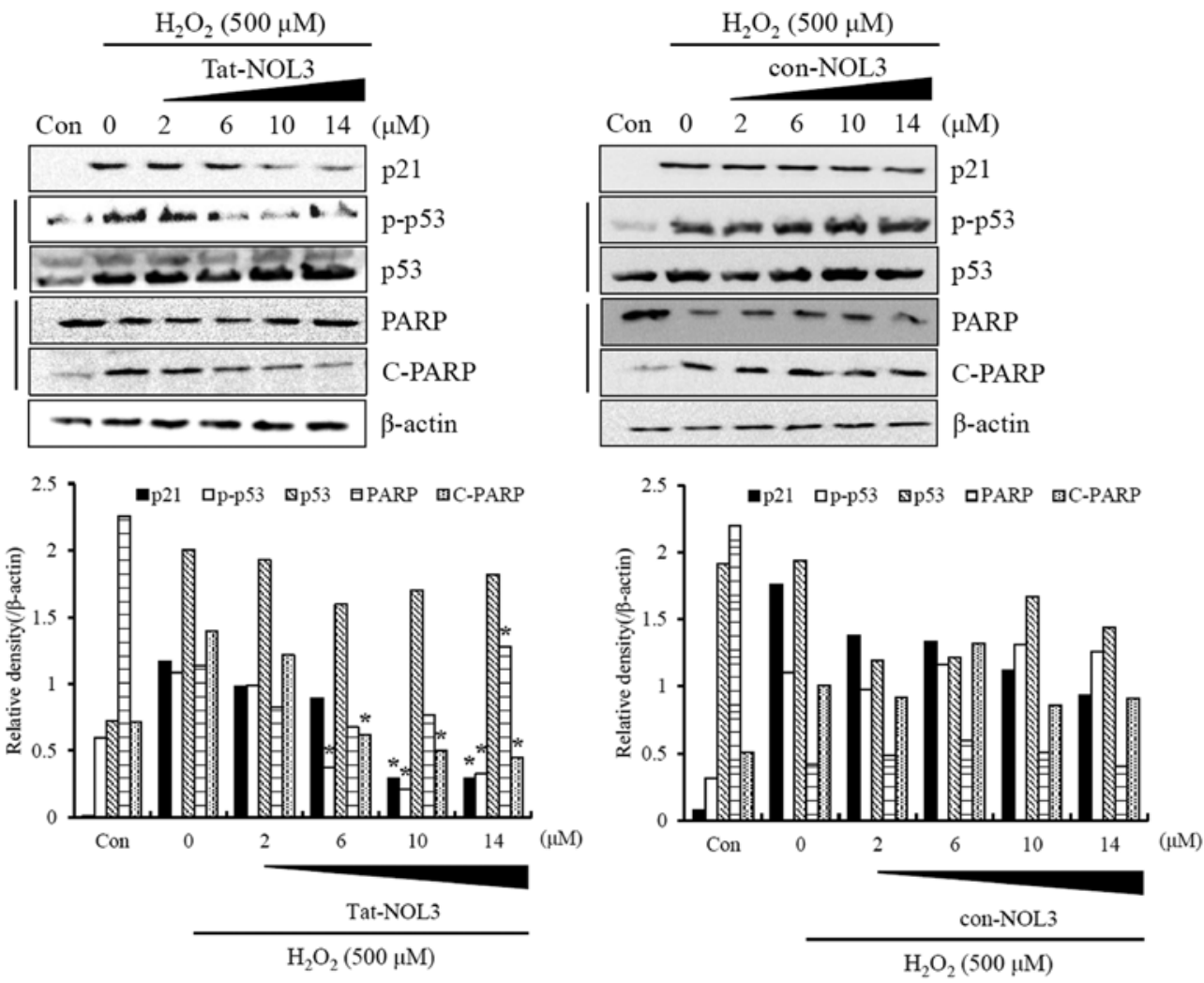

Figure 4. Inhibitory effects of Tat-fused (Tat)-NOL3 protein on $\mathrm{H}_{2} \mathrm{O}_{2}$-induced cell cycle arrest in HT22 cells. Following the treatment of HT22 cells with Tat-NOL3 protein for $1 \mathrm{~h}$, the cells were exposed to $500 \mu \mathrm{M} \mathrm{H}_{2} \mathrm{O}_{2}$. The protein levels of p21, phosphorylated (p-)p53, p53, PARP and cleaved (C-)PARP were evaluated by western blot analysis and band intensity was determined using densitometry. ${ }^{*} \mathrm{P}<0.01$, compared with $\mathrm{H}_{2} \mathrm{O}_{2}$-exposed cells; con-NOL3, control NOL3 .
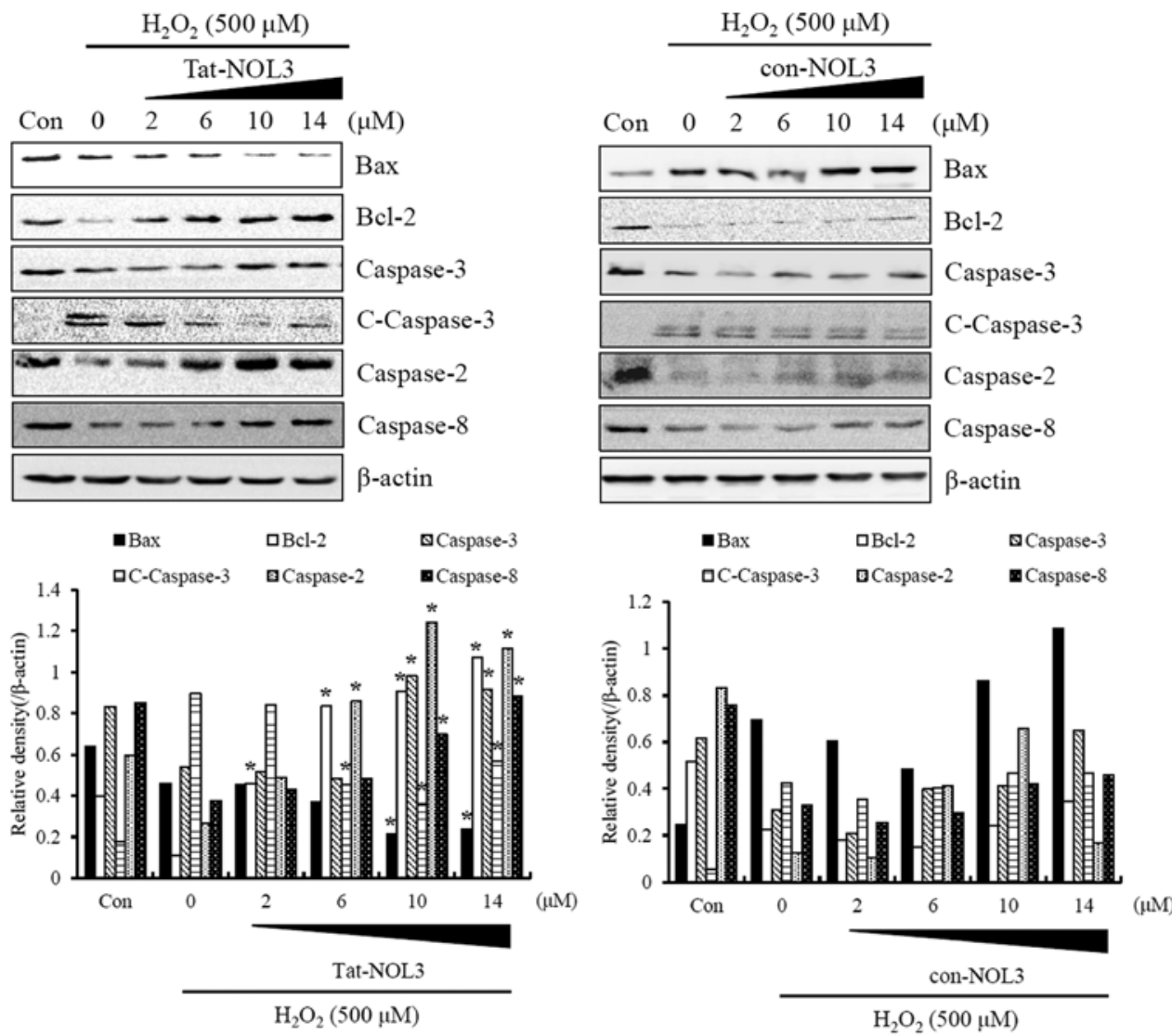

Figure 5. Tat-fused (Tat)-NOL3 protein inhibits the activation of $\mathrm{H}_{2} \mathrm{O}_{2}$-induced apoptosis. Following the treatment of HT22 cells with Tat-NOL3 protein for $1 \mathrm{~h}$, the cells were exposed to $500 \mu \mathrm{M} \mathrm{H}_{2} \mathrm{O}_{2}$. Extracts from the cells were prepared and the levels of Bax, Bcl-2, caspase-3, cleaved (C-)caspase-3, caspase-2 and -8 proteins were examined by western blot analysis and band intensity was determined using densitometry. " $\mathrm{P}<0.01$, compared with $\mathrm{H}_{2} \mathrm{O}_{2}$ treated cells; con-NOL3, control NOL3 


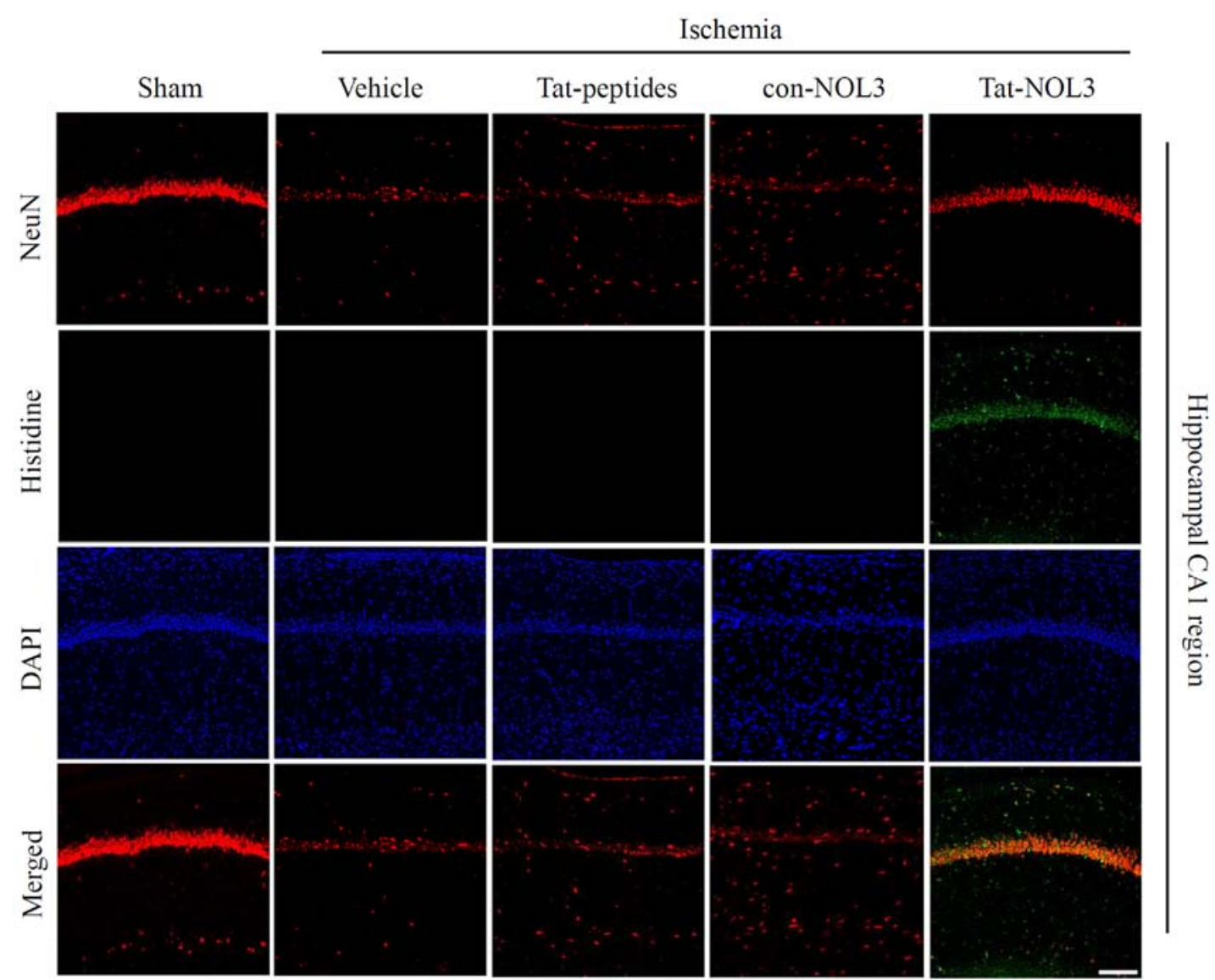

Figure 6. Effect of Tat-fused (Tat)-NOL3 protein on neuronal cell death in an animal model of forebrain ischemia. Gerbils were treated with a single injection of Tat-NOL3 $(2 \mathrm{mg} / \mathrm{kg})$ protein and sacrificed after 7 days. Hippocampal CA1 regions were stained with mouse anti-neuronal nuclei (NeuN) and anti-histidine antibody in sham-, vehicle-, Tat peptide-, control (con)-NOL3- and Tat-NOL3-treated ischemic animals. Scale bar, $50 \mu \mathrm{m}$.

protein selectively suppressed both ROS-induced intrinsic and extrinsic apoptotic pathways through the downregulation of pro-apoptotic proteins and the upregulation of anti-apoptotic proteins.

Transduced Tat-NOL3 protects against neuronal cell death in a model of ischemic injury. Ischemia-reperfusion results in a decrease of neurons in the CA1 region of the hippocampus (43). NeuN is used as a marker for neurons (44). Thus, we examined whether transduced Tat-NOL3 protein protects against ischemic injury-induced neuronal cell death in the hippocampal CA1 regions. Cell viability was determined by immunohistochemistry using a His antibody and NeuN stains. As shown in Fig. 6, transduced Tat-NOL3 protein significantly inhibited neuronal cell death in the CA1 regions compared with the vehicle-, Tat peptide-, and con-NOL3-treated groups. Consistent with these results, $\mathrm{CV}$ staining also revealed that transduced Tat-NOL3 protein markedly increased neuronal cell viability in the hippocampal CA1 region. However, Tat peptide- and con-NOL3 protein-treated groups did not show the same effect on neuronal cell viability and showed similar levels to the vehicle control group (Fig. 7).

Iba- 1 is expressed in microglia and may be associated with the activation of microglia in the ischemic brain (45). Neuronal injury was stained and detected using FJB. GFAP is a specific marker for astrocytes, which are one of the predominant types of glial cells (46). Thus, we also performed Iba-1, GFAP, and FJB staining in the hippocampal CA1 regions of the animal brains (Fig. 7). In the vehicle-, con-NOL3 protein-, and Tat peptide-treated groups, Iba-1, GFAP, and FJB fluorescence was strongly detected. However, Iba-1, GFAP, and FJB fluorescence were significantly decreased by transduced Tat-NOL3 protein. These results indicate that ischemic injury induced microglial activation (Iba-1), astrocyte accumulation (GFAP), and neuronal injury (FJB) in the CA1 region of the hippocampus. However, transduced Tat-NOL3 protein protected against neuronal cell death resulting from ischemic injury in the hippocampal CA1 region by reducing the activation of astrocytes and microglia.

\section{Discussion}

Ischemia-reperfusion injury causes neuronal death in the hippocampal CA1 region through oxidative stress-induced apoptosis. Oxidative stress is associated with mitochondrial dysfunction and increased ROS production resulting from the ischemic cascade initiated due to oxygen reperfusion following ischemia (47). Ischemia-reperfusion triggers two apoptotic pathways. The intrinsic mitochondrial pathway causes the activation of Bcl-2 and the translocation of Bax into mitochondria which results in the release of cytochrome $c$ and the activation of caspase-3 (48). The extrinsic apoptotic pathway is mediated by the activation of cell surface death receptors which activate 


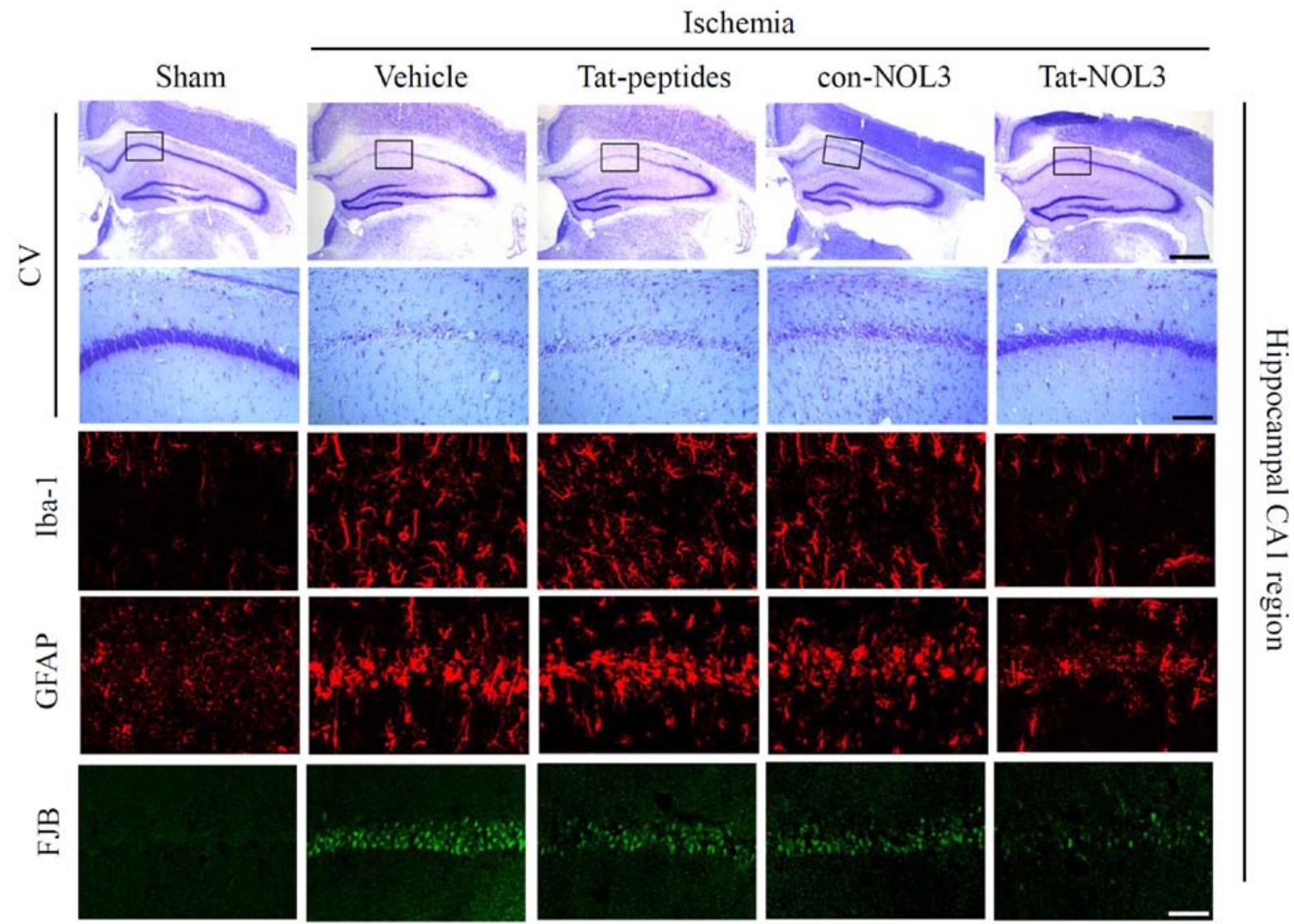

Figure 7. Effect of Tat-fused (Tat)-NOL3 protein on neuronal cell death and activation of astrocytes and microglia following ischemic insults. Gerbils were treated with a single injection of Tat-NOL3 $(2 \mathrm{mg} / \mathrm{kg}$ ) protein and sacrificed after 7 days. Hippocampal CA1 regions were stained with cresyl violet (CV), ionized calcium-binding adapter molecule 1 (Iba-1), glial fibrillary acidic protein (GFAP), and Fluoro-Jade B (FJB) in sham-, vehicle-, Tat peptide-, control (con)-NOL3- and Tat-NOL3-treated ischemic animals. The black boxes in the first row of images denote the areas shown at higher magnification in the second row of images. Scale bar, $100 \mu \mathrm{m}$ except for $50 \mu \mathrm{m}$ when at higher magnification.

caspase- 8 and subsequently activate caspase-3 (49). It is important to note that p53 is involved in both the intrinsic and the extrinsic apoptotic pathways (50).

Excessive ROS are generated from mitochondria and are also stimuli of the intrinsic mitochondrial pathway (3), whereas the effect of intracellular ROS on the extrinsic apoptotic pathway remains unclear. Notably, recent evidence suggests that ROS activate sphingomyelinase which is responsible for the generation of ceramide that is involved in the induction of Fas receptor and Fas ligand. Moreover, ROS sensitize cancer cells to TRAIL-induced apoptosis $(5,20)$. This implies that ROS may affect not only the intrinsic mitochondrial pathway but also the extrinsic apoptotic pathway. In this study, we examined whether transduced Tat-NOL3 protein plays a role in the intrinsic and extrinsic apoptotic pathways under conditions of oxidative stress.

To transduce NOL3 protein into hippocampal neuronal HT22 cells as well as gerbil brains in a model of forebrain ischemia, we prepared Tat-NOL3. Tat-NOL3 protein transduced into the HT22 cells in a time- and dose-dependent manner. To examine the effects of Tat-NOL3 protein on stressinduced HT22 cell death, we exposed the cells to $\mathrm{H}_{2} \mathrm{O}_{2}$. The $\mathrm{H}_{2} \mathrm{O}_{2}$-exposed HT22 cells exhibited intracellular ROS accumulation and disruption of $\Delta_{\Psi_{\mathrm{m}}}$ leading to intrinsic mitochondrial apoptosis. However, the transduction of Tat-NOL3 protein into the HT22 cells exposed to $\mathrm{H}_{2} \mathrm{O}_{2}$, resulted in reduced levels of intracellular ROS and recovery of $\Delta_{\Psi_{\mathrm{m}}}$ to normal levels, suggesting that Tat-NOL3 protein inhibits mitochondrial dysfunction. Although the exact mechanisms responsible for the protective effects of Tat-NOL3 in $\mathrm{H}_{2} \mathrm{O}_{2}$-induced neuronal cell death warrant further study, these results indicate that Tat-NOL3 may control complex cascades of $\mathrm{H}_{2} \mathrm{O}_{2}$ production that are mediated by the inhibition of intrinsic mitochondrial apoptosis. Consistent with this observation, the transduction of Tat-NOL3 protein to the cytosol of the $\mathrm{H}_{2} \mathrm{O}_{2}$-exposed HT22 cells resulted in decreased DNA fragmentation and the inactivation of p53. Additionally, the expression levels of oxidative DNA damage-related proteins, $\mathrm{p} 21^{\text {cip1/waf1 }}$ and cleaved PARP, were regulated by Tat-NOL3 protein. These results indicate that Tat-NOL3 inhibited the $\mathrm{H}_{2} \mathrm{O}_{2}$-mediated loss of p21 and cleavage of PARP.

Next, we examined the interplay between Tat-NOL3 protein and the intrinsic and extrinsic apoptotic pathways through interactions with caspases and apoptosis-related proteins. Transduced Tat-NOL3 protein protected against the oxidative-stress induced activation of the intrinsic apoptotic pathway through the inhibition of mitochondrial damage and the regulation of pro- or anti-apoptotic protein expression including Bax and Bcl-2 protein. Tat-NOL3 protein increased anti-apoptotic Bcl-2 protein expression levels whereas pro-apoptotic protein Bax expression levels were reduced by the inhibition of excessive ROS generation. Furthermore, Tat-NOL3 protein 
inhibited the extrinsic apoptotic pathway by activating the caspase cascade including caspase-3.

Apoptotic cell death is initiated through the extrinsic and intrinsic pathways. Previous research has shown that NOL3 inhibits the extrinsic pathway by activating caspase- 8 while activating the intrinsic pathway through the regulation of Bax, p53, and mitochondrial responses to stress stimuli (51). Although further study is merited in order to understand the precise mechanism, other studies have suggested that NOL3 protects against cell death by regulating the extrinsic and intrinsic apoptosis pathways through a multifunctional mechanism (52). In agreement with the other studies, the results of this study demonstrate that transduced Tat-NOL3 protein protected against oxidative stress-induced cell death by inhibiting the intrinsic and extrinsic apoptotic pathways and suggest that transduced Tat-NOL3 protein inhibited $\mathrm{H}_{2} \mathrm{O}_{2}$-induced neuronal cell death through the regulation of apoptotic signal pathways.

The ischemia-reperfusion model leads to the delayed degeneration of pyramidal neurons in the CA1 region of the hippocampus (53). In previous studies, we demonstrated that transduced PTD fusion proteins protect against delayed pyramidal neuronal degeneration in the hippocampal CA1 region in an animal model of ischemia $(23,33)$. Thus, the protective effects of Tat-NOL3 protein against ischemic damage were determined by immunohistochemistry. To confirm that transduced Tat-NOL3 protein protects against neuronal damage in an animal model of ischemia, Tat-NOL3 proteins were intraperitoneally administered $30 \mathrm{~min}$ after the induction of ischemia. Seven days after ischemia, the protective effects of Tat-NOL3 proteins were confirmed by CV and NeuN immunohistochemistry. Neuronal cell viability was significantly increased in the hippocampal CA1 regions of the Tat-NOL3 protein-treated group. These results indicate that Tat-NOL3 protein transduced into the CA1 region of the animal brain and protected against neuronal cell death. We also demonstrated that CA1 pyramidal neurons were protected against ischemic damage in the Tat-NOL3 protein-treated groups. Activated astrocytes and microglia were significantly decreased in the Tat-NOL3 protein-treated groups compared with the vehicle-treated groups. These results indicate that transduced Tat-NOL3 protein protected against ischemic damage by reducing the activation of astrocytes and microglia. Thus, we suggest that transduced Tat-NOL3 protein may be a useful agent for preventing ischemic damage.

In conclusion, we demonstrated that Tat-NOL3 protein transduced into HT22 cells and protected against neuronal cell death induced by oxidative stress through the regulation of apoptotic signaling pathways. In addition, Tat-NOL 3 protein markedly protected against neuronal cell death in the CA1 region of the hippocampus by reducing the activation of astrocytes and microglia. Thus, we suggest that Tat-NOL3 protein may be a therapeutic agent against ischemia and oxidative stress-induced neuronal cell death.

\section{Acknowledgements}

The present study was supported by a Priority Research Centers Program grant (no. 2009-0093812) through the National Research Foundation of Korea funded by the Ministry of Science, ICT and Future Planning, and in part by the BioGreen21 Program (no. PJ01121401) of the Rural Development Administration, Republic of Korea, and by a Hallym University Research Fund (no. HRF-G-2015-2).

\section{References}

1. Smith JA, Park S, Krause JS and Banik NL: Oxidative stress, DNA damage, and the telomeric complex as therapeutic targets in acute neurodegeneration. Neurochem Int 62: 764-775, 2013.

2. Simonian NA and Coyle JT: Oxidative stress in neurodegenerative diseases. Annu Rev Pharmacol Toxicol 36: 83-106, 1996.

3. Niizuma K, Endo H and Chan PH: Oxidative stress and mitochondrial dysfunction as determinants of ischemic neuronal death and survival. J Neurochem 109 (Suppl 1): 133-138, 2009.

4. Schaller B and Graf R: Cerebral ischemia and reperfusion: the pathophysiologic concept as a basis for clinical therapy. J Cereb Blood Flow Metab 24: 351-371, 2004.

5. D'Autréaux B and Toledano MB: ROS as signalling molecules: mechanisms that generate specificity in ROS homeostasis. Nat Rev Mol Cell Biol 8: 813-824, 2007.

6. Mronga T, Stahnke T, Goldbaum O and Richter-Landsberg C: Mitochondrial pathway is involved in hydrogen-peroxide-induced apoptotic cell death of oligodendrocytes. Glia 46: 446-455, 2004.

7. Zhang YQ and Herman B: ARC protects rat cardiomyocytes against oxidative stress through inhibition of caspase- 2 mediated mitochondrial pathway. J Cell Biochem 99: 575-588, 2006.

8. Wang JX, Li Q and Li PF: Apoptosis repressor with caspase recruitment domain contributes to chemotherapy resistance by abolishing mitochondrial fission mediated by dynamin-related protein-1. Cancer Res 69: 492-500, 2009.

9. Lejay A, Meyer A, Schlagowski AI, Charles AL, Singh F, Bouitbir J,Pottecher J, Chakfé N, Zoll J and Geny B: Mitochondria: mitochondrial participation in ischemia-reperfusion injury in skeletal muscle. Int J Biochem Cell Biol 50: 101-105, 2014.

10. Ow YP, Green DR, Hao Z and Mak TW: Cytochrome $c$ : functions beyond respiration. Nat Rev Mol Cell Biol 9: 532-542, 2008.

11. Li J and Yuan J: Caspases in apoptosis and beyond. Oncogene 27: 6194-6206, 2008.

12. Norbury CJ and Zhivotovsky B: DNA damage-induced apoptosis. Oncogene 23: 2797-2808, 2004.

13. Zhivotovsky B and Orrenius S: Caspase-2 function in response to DNA damage. Biochem Biophys Res Commun 331: 859-867, 2005.

14. Neuss M, Monticone R, Lundberg MS, Chesley AT, Fleck E and Crow MT: The apoptotic regulatory protein ARC (apoptosis repressor with caspase recruitment domain) prevents oxidant stress-mediated cell death by preserving mitochondrial function. J Biol Chem 276: 33915-33922, 2001.

15. Razorenova OV, Castellini L, Colavitti R, Edgington LE, Nicolau M, Huang X, Bedogni B, Mills EM, Bogyo M and Giaccia AJ: The apoptosis repressor with a CARD domain (ARC) gene is a direct hypoxia-inducible factor 1 target gene and promotes survival and proliferation of VHL-deficient renal cancer cells. Mol Cell Biol 34: 739-751, 2014.

16. Embury J, Klein D, Pileggi A, Ribeiro M, Jayaraman S, Molano RD, Fraker C, Kenyon N, Ricordi C, Inverardi L and Pastori RL: Proteins linked to a protein transduction domain efficiently transduce pancreatic islets. Diabetes 50: 1706-1713, 2001.

17. Wadia JS and Dowdy SF: Protein transduction technology. Curr Opin Biotechnol 13: 52-56, 2002.

18. Kubo E, Fatma N, Akagi Y, Beier DR, Singh SP and Singh DP: TAT-mediated PRDX6 protein transduction protects against eye lens epithelial cell death and delays lens opacity. Am J Physiol Cell Physiol 294: C842-C855, 2008.

19. Dietz GP: Cell-penetrating peptide technology to deliver chaperones and associated factors in diseases and basic research. Curr Pharm Biotechnol 11: 167-174, 2010.

20. Kim DW, Lee SH, Jeong MS, Sohn EJ, Kim MJ, Jeong HJ, An JJ, Jang SH, Won MH and Hwang IK: Transduced Tat-SAG fusion protein protects against oxidative stress and brain ischemic insult. Free Radic Biol Med 48: 969-977, 2010.

21. van den Berg A and Dowdy SF: Protein transduction domain delivery of therapeutic macromolecules. Curr Opin Biotechnol 22: 888-893, 2011.

22. Kim DW, Lee SH, Ku SK, Lee JE, Cha HJ, Youn JK, Kwon HY, Park JH, Park EY, Cho SW, et al: The effects of PEP-1-FK506BP on dry eye disease in a rat model. BMB Rep 48: 153-158, 2015. 
23. Shin MJ, Kim DW, Lee YP, Ahn EH, Jo HS, Kim DS, Kwon OS, Kang TC, Cho YJ, Park J, et al: Tat-glyoxalase protein inhibits against ischemic neuronal cell damage and ameliorates ischemic injury. Free Radic Biol Med 67: 195-210, 2014.

24. Eom SA, Kim DW, Shin MJ, Ahn EH, Chung SY, Sohn EJ, Jo HS, Jeon SJ, Kim DS, Kwon HY, et al: Protective effects of PEP-1-Catalase on stress-induced cellular toxicity and MPTP-induced Parkinson's disease. BMB Rep 48: 395-400, 2015.

25. Kim HR, Kim DW, Jo HS, Cho SB, Park JH, Lee CH, Choi YJ, Yeo EJ, Park SY, Kim ST, et al: Tat-biliverdin reductase A inhibits inflammatory response by regulation of MAPK and $\mathrm{NF}-\kappa \mathrm{B}$ pathways in Raw 264.7 cells and edema mouse model. Mol Immunol 63: 355-366, 2015.

26. Kwon HY, Eum WS, Jang HW, Kang JH, Ryu J, Ryong Lee B, Jin LH, Park J and Choi SY: Transduction of $\mathrm{Cu}, \mathrm{Zn}$-superoxide dismutase mediated by an HIV-1 Tat protein basic domain into mammalian cells. FEBS Lett 485: 163-167, 2000.

27. Bradford MM: A rapid and sensitive method for the quantitation of microgram quantities of protein utilizing the principle of protein-dye binding. Anal Biochem 72: 248-254, 1976.

28. Ju SM, Youn GS, Cho YS, Choi SY and Park J: Celastrol ameliorates cytokine toxicity and pro-inflammatory immune responses by suppressing NF- $\kappa \mathrm{B}$ activation in RINm5F beta cells. BMB Rep 48: 172-177, 2015.

29. Shehzad A, Lee J and Lee YS: Autocrine prostaglandin $\mathrm{E}_{2}$ signaling promotes promonocytic leukemia cell survival via COX-2 expression and MAPK pathway. BMB Rep 48: 109-114, 2015.

30. Park G and Oh MS: Acceleration of heat shock-induced collagen breakdown in human dermal fibroblasts with knockdown of NF-E2-related factor 2. BMB Rep 48: 467-472, 2015.

31. Im CN and Seo JS: Overexpression of tumor necrosis factor receptor-associated protein 1 (TRAP1), leads to mitochondrial aberrations in mouse fibroblast NIH/3T3 cells. BMB Rep 47: 280-285, 2014

32. Lee YJ, Lee YJ and Lee SH: Resveratrol and clofarabine induces a preferential apoptosis-activating effect on malignant mesothelioma cells by Mcl-1 down-regulation and caspase-3 activation. BMB Rep 48: 166-171, 2015.

33. Kim YN, Jung HY, Eum WS, Kim DW, Shin MJ, Ahn EH, Kim SJ, Lee CH, Yong JI, Ryu EJ, et al: Neuroprotective effects of PEP-1carbonyl reductase 1 against oxidative-stress-induced ischemic neuronal cell damage. Free Radic Biol Med 69: 181-196, 2014.

34. Lee SJ and Park JW: Enhancement of UVB radiation-mediated apoptosis by knockdown of cytosolic NADP ${ }^{+}$-dependent isocitrate dehydrogenase in HaCaT cells. BMB Rep 47: 209-214, 2014.

35. Hwang IK, Yoo KY, Kim DW, Lee CH, Choi JH, Kwon YG Kim YM, Choi SY and Won MH: Changes in the expression of mitochondrial peroxiredoxin and thioredoxin in neurons and glia and their protective effects in experimental cerebral ischemic damage. Free Radic Biol Med 48: 1242-1251, 2010.

36. Jeong HJ, Yoo DY, Kim DW, Yeo HJ, Cho SB, Hyeon J, Park JH Park J, Eum WS, Hwang HS, et al: Neuroprotective effect of PEP-1-peroxiredoxin2 on CA1 regions in the hippocampus against ischemic insult. Biochim Biophys Acta 1840: 2321-2330, 2014.

37. Choi DW: Ischemia-induced neuronal apoptosis. Curr Opin Neurobiol 6: 667-672, 1996.
38. MacManus JP, Buchan AM, Hill IE, Rasquinha I and Preston E: Global ischemia can cause DNA fragmentation indicative of apoptosis in rat brain. Neurosci Lett 164: 89-92, 1993

39. Zhang Y, Zhang Z and Yan H: Simvastatin inhibits ischemia/reperfusion injury-induced apoptosis of retinal cells via downregulation of the tumor necrosis factor- $\alpha$ /nuclear factor- $\kappa \mathrm{B}$ pathway. Int J Mol Med 36: 399-405, 2015.

40. Fussenegger M and Bailey JE: Molecular regulation of cell-cycle progression and apoptosis in mammalian cells: implications for biotechnology. Biotechnol Prog 14: 807-833, 1998.

41. Martinez LA, Yang J, Vazquez ES, Rodriguez-Vargas MC, Olive M, Hsieh JT, Logothetis CJ and Navone NM: p21 modulates threshold of apoptosis induced by DNA-damage and growth factor withdrawal in prostate cancer cells. Carcinogenesis 23: 1289-1296, 2002.

42. Gough DR and Cotter TG: Hydrogen peroxide: a Jekyll and Hyde signalling molecule. Cell Death Dis 2: e213-e218, 2011.

43. Hara K, Yasuhara T, Matsukawa N, Maki M, Masuda T, Yu G, Xu L, Tambrallo L, Rodriguez NA, Stern DM, et al: Hippocampal CA1 cell loss in a non-human primate model of transient global ischemia: A pilot study. Brain Res Bull 74: 164-171, 2007.

44. Schmued LC and Hopkins KJ: Fluoro-Jade B: a high affinity fluorescent marker for the localization of neuronal degeneration. Brain Res 874: 123-130, 2000.

45. Broughton BRS, Reutens DC and Sobey CG: Apoptotic mechanisms after cerebral ischemia. Stroke 40: e331-e339, 2009.

46. Rossi DJ, Brady JD and Mohr C: Astrocyte metabolism and signaling during brain ischemia. Nat Neurosci 10: 1377-1386, 2007.

47. Chong ZZ, Li F and Maiese K: Oxidative stress in the brain: novel cellular targets that govern survival during neurodegenerative disease. Prog Neurobiol 75: 207-246, 2005.

48. Swanton E, Savory P, Cosulich S, Clarke P and Woodman P. Bcl-2 regulates a caspase-3/caspase-2 apoptotic cascade in cytosolic extracts. Oncogene 18: 1781-1787, 1999.

49. Fulda S and Debatin KM: Extrinsic versus intrinsic apoptosis pathways in anticancer chemotherapy. Oncogene 25: 4798-4811, 2006.

50. Li YZ, Lu DY, Tan WQ, Wang JX and Li PF: p53 initiates apoptosis by transcriptionally targeting the antiapoptotic protein ARC. Mol Cell Biol 28: 564-574, 2008.

51. Danial NN and Korsmeyer SJ: Cell death: critical control points. Cell 116: 205-219, 2004

52. Wu L, Nam YJ, Kung G, Crow MT and Kitsis RN: Induction of the apoptosis inhibitor ARC by Ras in human cancers. J Biol Chem 285: 19235-19245, 2010.

53. Konaka K, Ueda H, Li JY, Matsumoto M, Sakoda S and Yanagihara T: $\mathrm{N}$-acetylaspartate to total creatine ratio in the hippocampal CA1 sector after transient cerebral ischemia in gerbils: influence of neuronal elements, reactive gliosis, and tissue atrophy. J Cereb Blood Flow Metab 23: 700-708, 2003. 